\title{
Translation into Arabic and validation of the Patient Assessment of Care for Chronic Conditions questionnaire for diabetes
}

Nouf Alharbi, ${ }_{1}^{1}$ Nada Alsubki, ${ }^{1}$ Fatmah Alotabi, ${ }^{2}$ Mohammed Alotabi, ${ }^{3}$ Norah Alhrabi, ${ }^{4}$ Simon de Lusgnian ${ }^{5}$ and Simon Jonas ${ }^{6}$

${ }^{1}$ Department of Health Sciences, College of Applied Studies and Community Service, King Saud University, Riyadh, Saudi Arabia. ${ }^{2}$ Quality Management Department, King Khaled Eye Specialist Hospital, Riyadh, Saudi Arabia. ${ }^{3}$ Department of Computer Science, University of Tabuk, Tabuk, Saudi Arabia. ${ }^{4}$ Executive Administration of Medical Affairs, King Fahad Medical City, Riyadh, Saudi Arabia. ${ }^{5}$ Department of Clinical and Experimental Medicine, University of Surrey, Guildford, United Kingdom. ${ }^{6}$ Center for Healthcare Innovation and Delivery Science, New York University, New York, United States of America. (Correspondence to: Nouf Alharbi: noufsahal@ksu.edu.sa).

Background: The Patient Assessment of Care for Chronic Conditions (PACIC-5As) is a questionnaire developed in English and designed to evaluate the health care experiences of people living with chronic conditions such as diabetes.

Aims: This study aimed to translate, culturally adapt and validate the PACIC-5As instrument for the Arab context in a sample of Saudi Arabian people with diabetes.

Methods: The PACIC-5As was translated into Arabic using a forward and backward translation process. The Arabic version was then validated with a sample of 557 Saudi Arabians with diabetes who were recruited from tertiary level diabetes centres in Riyadh between January and March 2018. In order to evaluate the psychometric properties of the Arabic version, Cronbach alphas and item correlations were determined and exploratory factor analysis was performed.

Results: The translated PACIC-5As had good psychometric quality. Cronbach alpha was $>0.9$ and the inter-item correlation ranged between 0.36 and 0.56. Exploratory factor analysis showed a single-factor structure.

Conclusion: An Arabic version of the PACIC-5As questionnaire is now available to assess the experience of patients with diabetes. The results of this study can be used to improve the quality of the delivery of health care in Arabic-speaking countries.

Keywords: diabetes, delivery of health care, surveys and questionnaires, translating, Saudi Arabia

Citation: Alharbi N; Alsubki N; Alotabi F; Alotabi M; Alhrabi N; de Lusgnian S; et al. Translation into Arabic and validation of the Patient Assessment of Care for Chronic Conditions questionnaire for diabetes. East Mediterr Health J. 2021;27(2):142-150. https://doi.org/10.26719/emhj.20.136

Received: 06/10/19; accepted: 03/02/20

Copyright (C) World Health Organization (WHO) 2021. Open Access. Some rights reserved. This work is available under the CC BY-NC-SA 3.0 IGO license (https://creativecommons.org/licenses/by-nc-sa/3.o/igo)

\section{Introduction}

Diabetes mellitus is one of the most prevalent chronic diseases. According to the International Diabetes Federation, the number of adults living with diabetes in 2017 was 451 million and this number is expected to reach 693 million by 2045 (1). Diabetes complications, which result from persistently high blood glucose levels that lead to micro- and macrovascular disease (e.g. retinopathy, and cardiovascular and renal diseases), have a devastating effect on those affected and their family members. In addition to the medical burden, the increasing prevalence of diabetes places a high economic burden on the individual, society and the health care system (2). Despite the large expenditure on managing and controlling diabetes worldwide, people living with the disease do not always receive optimal care (3). While some population-based health system models have adopted a structured and proactive approach to help reduce the incidence and burden of chronic diseases such as diabetes, others are still oriented towards the biomedical model of health care that emphasizes mainly the biological factors and ignores the social and psychological health influences (4).

The management of diabetes requires a comprehensive system of health care that incorporates diagnosis and ongoing medical monitoring and treatment (5). In order to guide the provision of health care for patients with chronic disease, the Health MacColl Institute for Healthcare Innovation developed the chronic care model. This model formulates and organizes the changes required in the health care system and by the patients to improve outcomes (6). These changes are accomplished by the integration of key components of the chronic care model: (i) organization of health care; (ii) delivery system design; (iii) decision support; (iv) patient selfmanagement; (v) community resources or linkages; and (vi) clinical information systems (7).

Complementary to the chronic care model, and to capture the perspective of service users, the Patient Assessment of Care for Chronic Conditions (PACIC) instrument was developed by the MacColl Center for Health Care Innovation. This tool is widely used to assess the "level of CCM-congruent activities that patients receive" (8). The original instrument consisted of five subscales that represent multiple features of providing patient-centred care consistent with the chronic care model. These subscales are: 1) Patient activation (enabling patient participation in their care), 2) Delivery system or practice design (promoting clinical care that is consistent with scientific evidence by sharing information with patient), 3) Goal setting or tailoring (establishing goals and plans with the patient to better manage their chronic condition), 4) Problem-solving (supporting the patient in managing health beyond their medical care) and 5) Follow-up or coordination (linking the patient with other health care services). Shortly after the dissemination of 
the results of the PACIC tool, six more subscales were added to the instrument. These scales followed the " $5 \mathrm{As}$ " principle that evaluated a model of behaviour change endorsed by the United States Preventative Services Taskforce. These principles are: assess (assessing the patient's level of behaviour, beliefs and motivation), advise (advising the patient based on personal health risks), agree (agreeing on a realistic set of goals with the patient), assist (assisting the patient to anticipate barriers and develop a specific action plan) and arrange (arranging follow-up support). The new instrument became known as PACIC-5As (8).

PACIC-5As has been translated into several languages, including (in order of date of translations) Spanish, Danish, French, Bengali and Malay (9-13). Given that seven Arab countries are among the top 20 countries with the highest prevalence of diabetes in the world, it would be useful to translate the PACIC-5As into Arabic (1). The aim of this study therefore was to translate and validate the PACIC-5As questionnaire with a sample of people living with diabetes. Saudi Arabia was a suitable country in which to validate the questionnaire because the number of people with diabetes is increasing there and is expected to continue to increase in the future (14).

\section{Methods}

\section{Instrument}

The PACIC-5As has 26 items that can be scored on a 5-point Likert scale: 1 (almost never), 2 (generally not), 3 (sometimes), 4 (most of the time) and 5 (almost always). The first 20 items can be categorized into five subscales based on the key elements of the chronic care model: patient activation (items 1-3); delivery system (items 4-6); goal setting (items 7-11); problem-solving (items 12-15); and follow-up (items 16-20). By including the additional six items, PACIC-5As can also be grouped into the 5As summary score as well as its subscales: assess (items 1, 11, 15, 20, 21); advise (items 4, 6, 9, 19, 24); agree (items 2, 3, 7, 8,25 ); assist (items 10, 12, 13, 14, 26); and arrange (items 16, $17,18,22,23)$. In addition, overall scores can be calculated for the PACIC (items 1-20) and the items related to the 5As (items 1-4 and 6-26) (8).

\section{Forward translation}

We followed the World Health Organization's (WHO) recommendation on the translation of instruments written in English into different languages to translate the PACIC-5As items into Arabic using a forward and backward multistep procedure (15). First, an expert panel of Saudi health specialists independently translated the list of items into Arabic. Second, the items were reviewed and compared with the original English terms, and disagreements were discussed and resolved. This process took over a week and resulted in the first draft of the Arabic PACIC-5As. Third, an external team of health researcher reviewed the translated version to evaluate the vocabulary, especially the health terms which might be under- stood differently by respondents because of dialectical variations in the Arabic-speaking countries.

\section{Content validity}

In order to determine whether the language, structure and the content of the Arabic PACIC-5As were appropriate to assess the quality of diabetes care in Arabs countries, we calculated the content validity index. This index consists of two domains: the clarity domain and the representativeness domain. We assessed these two domains for each item (item content validity index) and for the scale as a whole (scale content validity index). The item content validity index represents the proportion of reviewers who rated an item as very or highly relevant, while the scale content validity index is the averages of the scores of all the reviewers. An item content validity index agreement percentage of $78 \%$ or more indicates acceptable content validity. We estimated the overall scale content validity index score by taking the average of the items scores (16).

\section{Backward translation}

After we had validated the Arabic version of the PACIC-As, an independent professional translator, fluent in both Arabic and English, back translated the instrument into English, and minor changes were made. This translator was unaware of the original English PACIC-5As instrument.

\section{Validation with patients with diabetes}

Between January and March 2018, we invited all Saudi Arabian adults with type 1 or type 2 diabetes mellitus attending four outpatient tertiary diabetes centres in Riyadh to participate in the study. These centres provide specialized care for people with diabetes from first diagnosis to management of the condition, as well as preventative education and treatment services. While in the waiting area, we asked each participant to complete the questionnaire, provide the necessary demographic data and return the instrument at the end of their appointment. Previous studies aimed for a sample size of five times the number of PACIC variables (minimum of 130 participants) (9-13); our convenience sampling method resulted in 557 participants.

\section{Statistical analysis}

We used SPSS, version 20.0 for data entry and analysis. Statistical procedures included descriptive analysis of the PACIC-5As items, the subscales and the overall scales as well as the demographic characteristics of the participants. The PACIC-5As scores were calculated as means and standard deviations (SD) according to the instrument's instruction (8). Frequencies and percentages were used for the participants' demographic characteristics. We assessed the association between the PACIC-5As scores and the participants' characteristics using Spearman rank correlation. We considered a P-value of $\leq 0.05$ as statistically significant for all estimations. 
To assess the internal consistency of the PACIC5As, we calculated the Cronbach alpha for each of the subscales and the summary scores. An acceptable level of the Cronbach alpha is between 0.7 and 0.8 . We calculated the inter-item correlation to evaluate the extent to which items on the scales assess the same content; an acceptable level of inter-item correlation is between 0.2 and 0.4 (17). Finally, we performed an exploratory factor analysis using principle component analysis with promax rotation on (eigenvalue $>1$ ) and we also made scree plots of the eigenvalues; only variability factors $\geq 0.40$ were considered. We examined the sampling adequacy for the suitability of the data for factor analysis by calculating the Kaiser-Meyer-Olkin statistic (Kaiser-Meyer-Olkin $\geq 0.5$ which indicates the sampling was adequate).

\section{Ethical considerations}

The ethics committee of the University of Surrey approved the study (Reference number: EC/2014/14/FBEL) and we obtained written informed consent from all the participants.

\section{Results}

As shown in Table 1, most of the participants were males $(62.5 \%)$ and $48.7 \%$ were between 40 and 59 years old. Four hundred of these participants (71.8\%) had been diagnosed with diabetes more than 4 years earlier. We asked the participants to provide their last HbAic and/or fasting glucose level but only $5.9 \%(33 / 557)$ of them gave the number. We also asked the participants if they thought their blood glucose was controlled or uncontrolled; most $(82.2 \%)$ thought it was uncontrolled. Controlled blood glucose was defined as having an HbAlc $\leq 7 \%$ or fasting blood glucose $\leq 130 \mathrm{mg} / \mathrm{dL}$ (18). None of the characteristics of the participants was significantly associated with the PACIC-5As scores (Table 2).

Table 3 shows the results of the descriptive analysis and the internal consistency measures. The overall mean PACIC score was 2.52 (SD 0.74) with the PACIC subscale scores ranging from 2.10 (SD 0.76) (follow-up/ coordination) to 3.02 (SD 1.01) (delivery system/practice design). The individual items of the PACIC-5As score ranged from 1.31 (SD 0.59) for item 17 to 3.44 (SD1.25) for item 6 . The summary score of the 5 As ranged from 1.89 (SD 0.64) for arrange to 2.84 (SD 0.95) for advise.

\begin{tabular}{|c|c|}
\hline Characteristic & No. $(\%)(n=557)$ \\
\hline \multicolumn{2}{|l|}{$\operatorname{Sex}$} \\
\hline Male & $348(62.5)$ \\
\hline Female & $209(37.5)$ \\
\hline \multicolumn{2}{|l|}{ Age (years) } \\
\hline$<18$ & $2(0.4)$ \\
\hline $18-39$ & $227(40.8)$ \\
\hline $40-59$ & $271(48.7)$ \\
\hline$\geq 60$ & $57(10.2)$ \\
\hline \multicolumn{2}{|l|}{ Type of diabetes } \\
\hline Type 1 & $105(18.9)$ \\
\hline Type 2 & $452(81.1)$ \\
\hline \multicolumn{2}{|l|}{ Educational level } \\
\hline Less than high school & $36(6.5)$ \\
\hline High school & $72(12.9)$ \\
\hline Diploma $^{a}$ & $77(13.8)$ \\
\hline Bachelor & $270(48.5)$ \\
\hline Postgraduate & 102(18.3) \\
\hline \multicolumn{2}{|c|}{ Duration of diabetes (years) } \\
\hline$<1$ & $70(12.6)$ \\
\hline $2-3$ & $87(15.6)$ \\
\hline $4-10$ & $197(35.4)$ \\
\hline$>10$ & $203(36.4)$ \\
\hline \multicolumn{2}{|c|}{ Self-reported blood glucose control } \\
\hline Controlled & $99(17.8)$ \\
\hline Uncontrolled & $458(82.2)$ \\
\hline
\end{tabular}

The content validity analysis showed a representativeness score of $95.3 \%$ and a clarity score of $94.8 \%$, which indicated good agreement. The Cronbach alpha (internal consistency) for the overall Arabic PACIC questionnaire was 0.93 and 0.90 for the 5As summary score (Table 3). The Cronbach alpha scores for the subscales ranged between 0.70 and 0.82 . The average inter-item correlation ranged from 0.34 to 0.80 , with only two items with a value less than 0.4 - Goal setting/tailoring (item 11) and Assess (item 11). Item-total correlation (internal item convergence) was more than 0.4 in almost all items; only item 11 had a value lower than 0.4 .

Table 2 Correlation between demographic characteristics of participants and scores on the Patient Assessment of Care for Chronic Conditions (PACIC and PACIC-5As)

\begin{tabular}{lcccc} 
Demographic characteristic & PACIC score & \multicolumn{2}{c}{ 5As score } \\
Sex & r & P-value & r & -0.16 \\
Age & -0.12 & 0.39 & -0.03 & 0.29 \\
Type of diabetes & 0.07 & 0.25 & 0.08 & 0.53 \\
Duration of diabetes & 0.12 & 0.13 & -0.16 & 0.23 \\
Self-reported blood glucose control & -0.06 & 0.19 & -0.07 & 0.764 \\
\hline
\end{tabular}




\begin{tabular}{|c|c|c|c|c|c|}
\hline Scales/items & Mean score (SD) & $95 \%$ CI & $\begin{array}{l}\text { Item-scale } \\
\text { correlationa }\end{array}$ & $\begin{array}{c}\text { Item-total } \\
\text { correlationb }\end{array}$ & $\begin{array}{c}\text { Cronbach } \\
\text { alpha }\end{array}$ \\
\hline Overall PACIC score & $2.52(0.74)$ & $2.22-2.58$ & & & 0.93 \\
\hline Patient activation & $2.69(1.01)$ & $2.61-2.78$ & & & 0.76 \\
\hline 1 & 2.69 (1.11) & $2.60-2.78$ & 0.60 & 0.70 & \\
\hline 2 & $2.39(1.23)$ & $2.29-2.50$ & 0.65 & 0.65 & \\
\hline 3 & $3.01(1.37)$ & $2.90-3.13$ & 0.60 & 0.80 & \\
\hline Delivery system/practice design & $3.02(1.01)$ & $2.93-3.10$ & & & 0.79 \\
\hline 4 & $2.71(1.20)$ & $2.61-2.81$ & 0.54 & 0.63 & \\
\hline 5 & $2.90(1.23)$ & $2.81-3.01$ & 0.71 & 0.75 & \\
\hline 6 & $3.44(1.25)$ & $3.34-3.55$ & 0.73 & 0.73 & \\
\hline Goal setting/tailoring & $2.29(0.76)$ & $2.32-2.35$ & & & 0.74 \\
\hline 7 & $2.76(1.18)$ & $2.66-2.86$ & 0.59 & 0.64 & \\
\hline 8 & $2.63(1.26)$ & $2.52-2.73$ & 0.71 & 0.76 & \\
\hline 9 & $2.28(1.28)$ & $2.17-2.39$ & 0.61 & 0.71 & \\
\hline 10 & $1.40(0.67)$ & $1.35-1.46$ & 0.53 & 0.58 & \\
\hline 11 & $2.38(1.29)$ & $2.29-2.48$ & 0.35 & 0.37 & \\
\hline Problem-solving & $2.84(1.01)$ & $2.76-2.93$ & & & 0.77 \\
\hline 12 & $3.01(1.22)$ & $2.90-3.12$ & 0.45 & 0.52 & \\
\hline 13 & $2.59(1.32)$ & $2.49-2.69$ & 0.74 & 0.74 & \\
\hline 14 & $2.84(1.31)$ & $2.73-2.93$ & 0.73 & 0.83 & \\
\hline 15 & $2.94(1.44)$ & $2.82-3.06$ & 0.62 & 0.63 & \\
\hline Follow-up/coordination & $2.10(0.76)$ & $2.03-2.16$ & & & 0.82 \\
\hline 16 & $1.66(0.88)$ & $1.58-1.73$ & 0.70 & 0.73 & \\
\hline 17 & $1.31(0.59)$ & $1.26-1.36$ & 0.66 & 0.73 & \\
\hline 18 & $2.23(1.13)$ & $2.13-2.32$ & 0.63 & 0.63 & \\
\hline 19 & $2.84(1.13)$ & $2.73-2.96$ & 0.72 & 0.57 & \\
\hline 20 & $2.45(1.21)$ & $2.36-2.55$ & 0.75 & 0.77 & \\
\hline 5As score & $2.58(0.76)$ & $2.78-2.91$ & & & 0.90 \\
\hline Assess & $2.62(0.83)$ & $2.62-2.71$ & & & 0.70 \\
\hline 1 & $2.69(1.11)$ & $2.60-2.78$ & 0.58 & 0.69 & \\
\hline 11 & $2.38(1.29)$ & $2.29-2.48$ & 0.34 & 0.42 & \\
\hline 15 & $2.94(1.44)$ & $2.82-3.06$ & 0.54 & 0.62 & \\
\hline 20 & $2.45(1.21)$ & $2.36-2.55$ & 0.74 & 0.76 & \\
\hline 21 & $2.62(1.28)$ & $2.51-2.72$ & 0.59 & 0.68 & \\
\hline Advise & $2.84(0.95)$ & $2.74-2.94$ & & & 0.79 \\
\hline 4 & $2.71(1.20)$ & $2.61-2.81$ & 0.54 & 0.60 & \\
\hline 6 & $3.44(1.25)$ & $3.34-3.55$ & 0.65 & 0.72 & \\
\hline 9 & $2.28(1.28)$ & $2.17-2.39$ & 0.67 & 0.71 & \\
\hline 19 & $2.84(1.13)$ & $2.73-2.96$ & 0.47 & 0.56 & \\
\hline 24 & $2.95(1.26)$ & $2.85-3.06$ & 0.50 & 0.73 & \\
\hline Agree & $2.62(0.84)$ & $2.55-2.62$ & & & 0.78 \\
\hline 2 & 2.39 (1.23) & $2.29-2.50$ & 0.62 & 0.66 & \\
\hline 3 & $3.01(1.37)$ & $2.90-3.13$ & 0.53 & 0.62 & \\
\hline 7 & $2.76(1.18)$ & $2.66-2.86$ & 0.63 & 0.65 & \\
\hline 8 & $2.63(1.26)$ & $2.52-2.73$ & 0.76 & 0.76 & \\
\hline 25 & $2.30(1.06)$ & $2.21-2.39$ & 0.63 & 0.69 & \\
\hline Assist & $2.48(0.76)$ & $2.77-2.90$ & & & 0.72 \\
\hline 10 & $1.40(0.67)$ & $1.35-1.46$ & 0.52 & 0.58 & \\
\hline 12 & $3.01(1.22)$ & $2.90-3.12$ & 0.45 & 0.55 & \\
\hline
\end{tabular}




\begin{tabular}{|c|c|c|c|c|c|}
\hline Scales/items & Mean score (SD) & $95 \% \mathrm{CI}$ & $\begin{array}{l}\text { Item-scale } \\
\text { correlationa }\end{array}$ & $\begin{array}{l}\text { Item-total } \\
\text { correlationb }\end{array}$ & $\begin{array}{c}\text { Cronbach } \\
\text { alpha }\end{array}$ \\
\hline 13 & $2.59(1.32)$ & $2.49-2.69$ & 0.76 & 0.77 & \\
\hline 14 & $2.84(1.31)$ & $2.73-2.93$ & 0.64 & 0.70 & \\
\hline 26 & $2.55(1.26)$ & $2.45-2.66$ & 0.64 & 0.66 & \\
\hline Arrange & $1.89(0.64)$ & $1.83-1.94$ & & & 0.79 \\
\hline 16 & $1.66(0.88)$ & $1.58-1.73$ & 0.80 & 0.81 & \\
\hline 17 & $1.31(0.59)$ & $1.26-1.36$ & 0.67 & 0.70 & \\
\hline 18 & $2.23(1.13)$ & $2.13-2.32$ & 0.54 & 0.72 & \\
\hline 22 & $2.23(1.13)$ & $2.14-2.33$ & 0.41 & 0.54 & \\
\hline 23 & $2.05(1.05)$ & $1.69-2.14$ & 0.51 & 0.57 & \\
\hline
\end{tabular}

$S D=$ standard deviation; $C I=$ confidence interval.

${ }^{a}$ Correlation between item and referring scale.

${ }^{b}$ Correlation between item and overall PACIC score or 5 As summary score.

The feasibility of factor analysis (Bartlett test of sphericity) showed a good value (Kaiser-MeyerOlkin $\mathrm{PACIC}=0.86$ and Kaiser-Meyer-Olkin 5As $=0.85 ; P<0.001)$. We performed exploratory factor analysis with eigenvalue criterion and scree plots to identify the factorial pattern and best fit achieved by a unidimensional structure (Figure 1 and Figure 2). The principle component analysis with promax rotation identified one component with an eigenvalue of 9 which explained $47 \%$ of the variation of the PACIC structure and 11 eigenvalues that explained the $43 \%$ the variation of the 5As structure. Table 4 shows the result of factor loading of the 20 PACIC items and 26 PACIC-5As items. All factors of both the PACIC and 5As structures had a factor loading of more than $0.4 ; 95 \%(19 / 20)$ of factors in the PACIC were more than 0.5 and $92 \%(24 / 26)$ of factors in 5 As items were more than 0.5 .

\section{Discussion}

We successfully translated the PACIC-5As from English into Arabic. As these languages came from different sources, Semitic and Indo-European languages, we used a certified translation process to minimize the linguistics differences with regard to the culture conceptualization $(15,19)$. The psychometric properties of the Arabic questionnaire were validated through use with more than 500 people living with diabetes. We achieved satisfactory evidence on the psychometric properties of the Arabic version of the PACIC-5As, suggesting our approach had a certain degree of rigour.

The mean PACIC-5As values of previous studies conducted in the United States, Germany and Switzerland and the use of the questionnaire in the context of diabetes management were more than $3.0(8,20,21)$. Our results showed a lower PACIC score (2.52 out of 5). This value shows that Saudi Arabians living with diabetes perceived that they were receiving a low level of patient-centred,

Figure 1 Scree plot of Patient Assessment of Care for Chronic Conditions (PACIC)

10

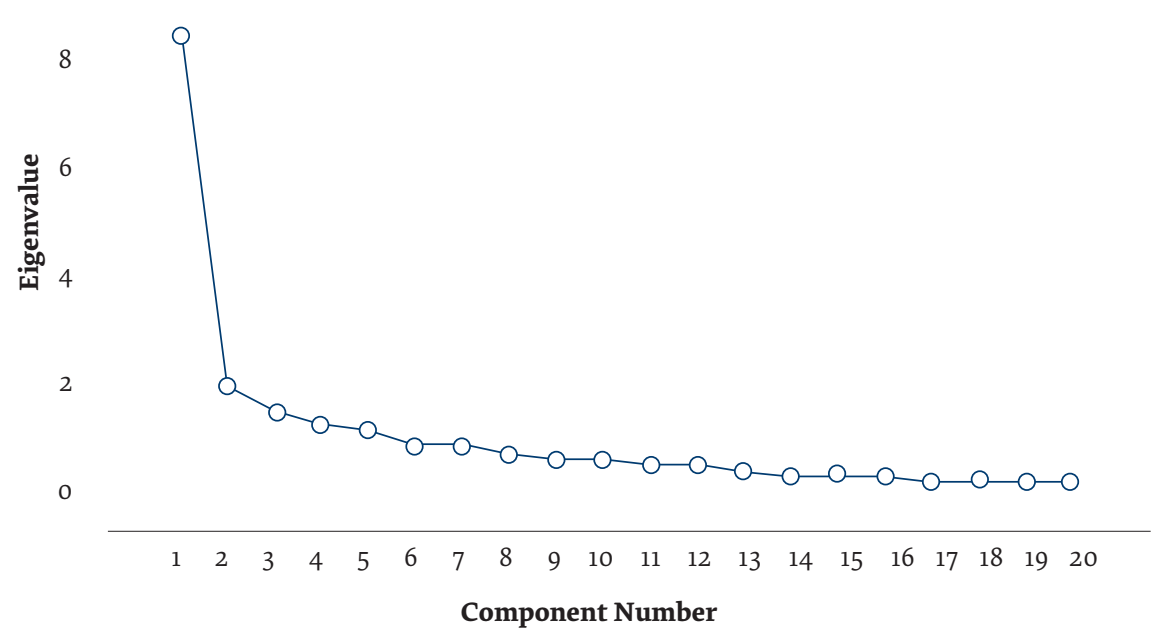




\section{Figure 2 Scree plot of Patient Assessment of Care for Chronic Conditions 5As (PACIC-5As)}

\section{Scree Plot}

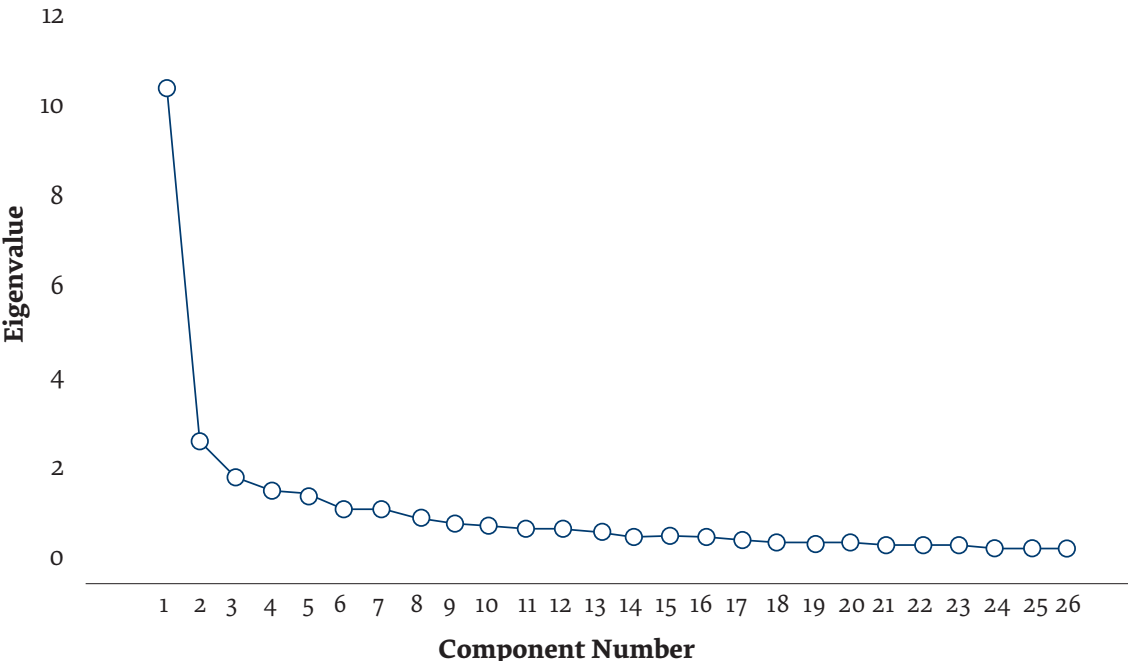

structured and collaborative care, according to the chronic care model. The developers of the original English version of the instrument noted that PACIC-5As scores should not be associated with demographic characteristics (8). Our finding concur with this as do the findings of other studies which showed that PACIC-5As scores were not

Table 4 Factor loading of Patient Assessment of Care for Chronic Conditions (PACIC) and PACIC-5As for one-factor-structure

$\begin{array}{lll}\text { Items } & \text { PACIC factor PACIC-5As factor }\end{array}$

loading loading

1. Asked for my ideas when we made a treatment plan

0.596

0.554

2. Given choices about treatment to think about

0.695

0.647

3. Asked to talk about any problems with my medicines or their effects

0.650

0.614

4. Given a written list of things I should do to improve my health

5. Satisfied that my care was well organised

0.725

0.705

6. Shown how what I did to take care of my illness influenced my condition

0.729

0.690

7. Asked to talk about my goals in caring for my illness

0.750

0.715

8. Helped to set specific goals to improve my eating or exercise

9. Given a copy of my treatment plan

0.732

10. Encouraged to go to a specific group or class to help me cope with my chronic illness

11. Asked questions, either directly or on a survey, about my health habits

12. Was sure that my doctor or nurse thought about my values and my traditions when they recommended treatments to me

13. Helped to make a treatment plan that I could carry out in my daily life

14. Helped to plan ahead so I could take care of my illness, even in hard times

15. Asked how my chronic illness affected my life

16. Contacted after a visit to see how things were going

17. Encouraged to attend programmes in the community that could help me

18. Referred to a dietitian, health educator or counsellor

19. Told how my visits with other types of doctors, an eye doctor or surgeon, helped my treatment

21. Asked what I would like to discuss about my illness at that visit

22. Asked how my work, family or social situation related to taking care of my illness

23. Helped to make plans for how to get support from my friends, family or the community 
significantly correlated with the sociodemographic characteristics of those completing the questionnaire $(9,22,23)$. This finding suggests that, overall, the translated questionnaire could be used in other Arab countries and still maintain its reliable psychometric properties.

The Cronbach alpha level for reliability of the instrument shown in our study was the same as the original instruments, but higher than some other translated instruments, namely the Spanish and Bengali versions (8,9,12). The Arabic PACIC-5As scales and subscales were similar to the Danish version, except that the goal-setting/tailoring and the problem-solving scales were lower than in the Danish version (10). With regard to construct validity of the PACIC, previous studies evaluated the structure of the instrument $(8-$ $10,11,13,20-31)$ and a few confirmed the five subscales of the questionnaire (five-factor structure) $(8,9,20,23)$. We identified five studies that evaluated the translated versions of the PACIC in different languages $(9,10,11,13,32)$. The Spanish and Malay versions identified five and three factors, respectively, while the French and Danish versions found a two-factor structure. In a study of the German version which explored the structure of both the PACIC and the 5As, a one-factor structure was found. We concluded that the previous validation studies showed mixed results, however, most were in accordance with our result of a one-factor structure (24,28-34).

There are more than 10 different language versions of the PACIC-5As instrument on the official website of the MacColl Center, and the validated Arabic PACIC5As is now available on the developer's website (35). We believe that this instrument can serve as an important patient-reported measure of care for diabetes in an Arab health care setting. The instrument can guide health professionals and policy-makers in Arabicspeaking countries to improve the health care delivery system for chronic diseases and enhance patients' satisfaction with their care. Further research in the form of a longitudinal study needs to be done in order to assess the reproducibility (test-retest reliability) of the instrument and to interview Arab patients to explore their understanding of the translated instrument.

Funding: The authors extend their appreciation to the Deanship of Scientific Research at King Saud University for funding this work through the: Thesis publication fund no (TPF-007).

Competing interests: None declared.

\section{Traduction en arabe et validation du questionnaire d'évaluation des soins pour les maladies chroniques par les patients, et en particulier pour le diabète}

\section{Résumé}

Contexte : Le questionnaire d'évaluation des soins pour les maladies chroniques par les patients (PACIC-5As) est un questionnaire mis au point en anglais et conçu pour évaluer les expériences en matière de soins de santé des personnes vivant avec des pathologies chroniques telles que le diabète.

Objectifs : La présente étude visait à traduire, adapter culturellement et valider l'instrument PACIC-5As pour le contexte arabe dans un échantillon de personnes saoudiennes atteintes de diabète.

Méthodes : Le PACIC-5As a été traduit en arabe à l'aide de la technique de traduction/rétro-traduction. La version arabe a ensuite été validée auprès d'un échantillon de 557 Saoudiens diabétiques recrutés dans des centres tertiaires de prise en charge du diabète à Riyad entre janvier et mars 2018. Afin d'évaluer les propriétés psychométriques de la version arabe, des alphas de Cronbach et des corrélations d'items ont été déterminés, et une analyse factorielle exploratoire a été réalisée.

Résultats : Le PACIC-5As traduit avait une bonne qualité psychométrique. Lalpha de Cronbach était supérieur à 0,9 et la corrélation inter-item était comprise entre 0,36 et 0,56. L'analyse factorielle exploratoire a montré une structure à facteur unique.

Conclusions : Une version arabe du questionnaire PACIC-5As est désormais disponible pour évaluer l'expérience des patients diabétiques. Les résultats de cette étude peuvent être utilisés pour améliorer la qualité de la prestation des soins de santé dans les pays arabophones.
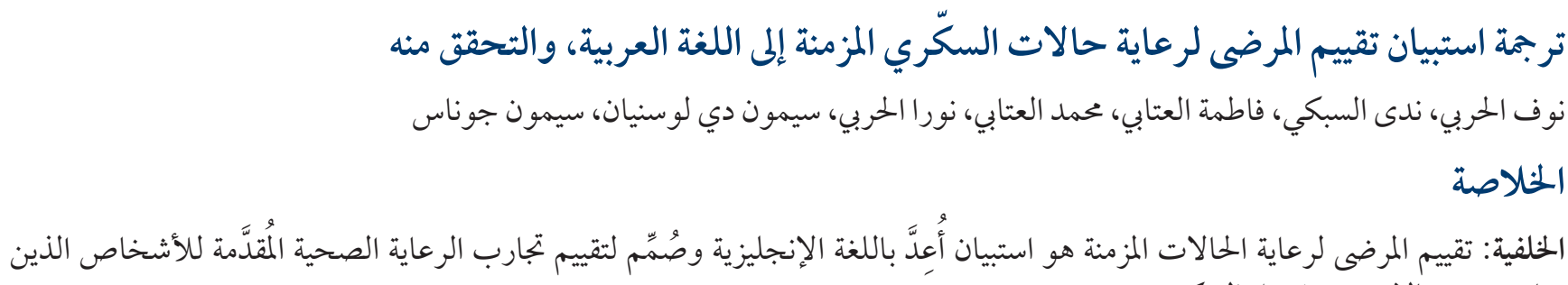

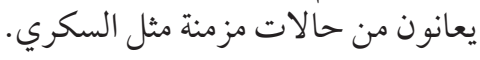

الأهداف: هدفت هذه الدراسة إلى ترجة أداة تقييم المرضى لرعاية الحالات المز منة، وتكييفها ثقافياً، و التحقق من مو اءمتها للسياق العربي في عينة من

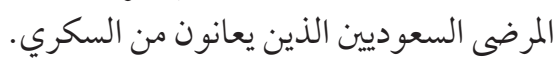




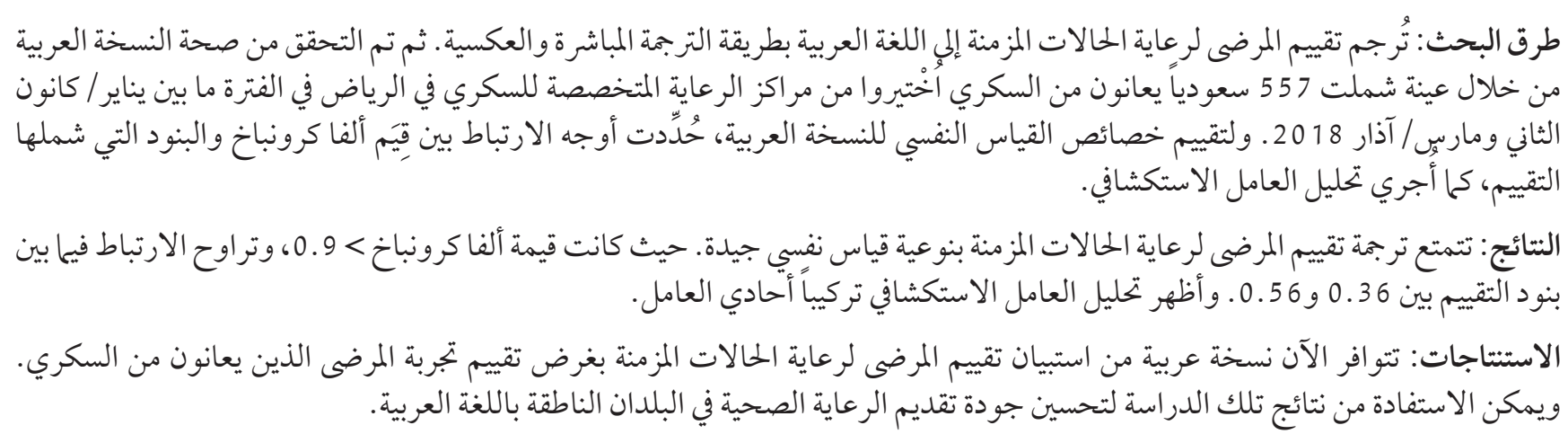

\section{References}

1. Cho NH, Shaw JE, Karuranga S, Huang Y, da Rocha Fernandes JD, Ohlrogge AW, et al. IDF diabetes atlas: global estimates of diabetes prevalence for 2017 and projections for 2045. Diabetes Res Clin Pract. 2018;138:271-81. http://doi.org/10.1016/j.diabres.2018.02.023

2. Zhang Y, Wieffer H, Modha R, Balar B, Pollack M, Krishnarajah G. The burden of hypoglycemia in type 2 diabetes: a systematic review of patient and economic perspectives. J Clin Outcomes Manag. 2010;17:547-57.

3. Alharbi NS, Alotaibi M, de Lusignan S. An analysis of health policies designed to control and prevent diabetes in Saudi Arabia. Global J Health Sci. 2016;8:233-41. http://dx.doi.org/10.5539/gjhs.v8n11p233

4. Innovative care for chronic conditions: building blocks for action: global report. Geneva: World Health Organization; 2002 (https://www.who.int/chp/knowledge/publications/icccglobalreport.pdf?ua=1, accessed 25 June 2020).

5. Atun R, Jaffar S, Nishtar S, Knaul FM, Barreto ML, Nyirenda M, et al. Improving responsiveness of health systems to noncommunicable diseases. Lancet. 2013;381:690-7. http://doi.org/10.1016/So140-6736(13)60063-X

6. Wagner EH, Austin BT, Davis C, Hindmarsh M, Schaefer J, Bonomi A. Improving chronic illness care: translating evidence into action. Health Affairs. 2001;20:64-78. http://doi.org/10.1377/hlthaff.20.6.64

7. Coleman D, Austin BT, Brach C, Wagner EH. Evidence on the chronic care model in the new millennium. Health Affairs. 2009;28:75-85. http://doi.org/10.1377/hlthaff.28.1.75

8. Glasgow RE, Whitesides H, Nelson CC, King DK Use of the Patient Assessment of Chronic Illness Care (PACIC) With Diabetic Patients: Relationship to Patient Characteristics, Receipt of Care, and Self-Management. Diabetes Care. 2005;28:2655-61. http:// doi.org/10.2337/diacare.28.11.2655

9. Aragones A, Schaefer EW, Stevens D, Gourevitch MN, Glasgow RE, Shah NR. Validation of the Spanish translation of the Patient Assessment of Chronic Illness Care (PACIC) survey. Prev Chronic Dis. 2008;5:1-10.

10. Maindal HT, Sokolowski I, Vedsted P. Adaptation, data quality and confirmatory factor analysis of the Danish version of the PACIC questionnaire. Eur J Public Health. 2012;22:31-6. http://doi.org/10.1093/eurpub/ckq188

11. Krucien N, Le Vaillant M, Pelletier-Fleury N. Adaptation and validation of the patient assessment of chronic illness care in the French context. BMC Health Serv Res. 2014;14:2-12. http://doi.org/10.1186/1472-6963-14-269.

12. Koley M, Saha S, Ghosh S, Nag G, Kundu M, Mondal R, Ali SS. Patient-assessed chronic illness care (PACIC) scenario in an Indian homeopathic hospital. J Tradit Complement Med. 2015;6:72-7. http://doi.org/10.1016/j.jtcme.2014.11.020

13. Abdul-Razak S, Ramli AS, Badlishah-Sham SF, Haniff J. Validity and reliability of the patient assessment on chronic illness care (PACIC) questionnaire: the Malay version. BMC Fam Pract. 2018;19:119. http://doi.org/10.1186/s12875-018-0807-5

14. Alharbi, NS, Almutari R, Jones S, Al-Daghri N, Khunti K, de Lusignan S. Trends in the prevalence of type 2 diabetes mellitus and obesity in the Arabian Gulf States: systematic review and meta-analysis. Diabetes Res Clin Pract. 2014;106:30-3. http://doi. org/10.1016/j.diabres.2014.08.019

15. Process of translation and adaptation of instruments [Internet]. Geneva: World Health Organization (http://www.who.int/substance_abuse/research_tools/translation/en/, accessed 5 July 2017).

16. Polit $\mathrm{D}$, Beck $\mathrm{C}$. The content validity index: are you sure you know what's being reported? Critique and recommendations. Res Nurs Health. 2006;29:489-97. http://doi.org/10.1002/nur.20147

17. Munro B. Statistical methods for health-care research, 5th edition. Philadelphia: Lippincott Williams \& Wilkins; 2005.

18. American Diabetes Association. Standards of medical care in diabetes. Diabetes Care. 2011;34:11-61. http://doi.org/10.2337/ dc11-Soo4

19. Bahameed A. Hindrances in Arabic-English intercultural translation. Translation J. 2008;12:1-6.

20. Frei A, Senn O, Huber F, Vecellio M, Steurer J, Woitzek K, et al. Congruency of diabetes care with the Chronic Care Model in different Swiss health care organisations from the patients' perspective: a cross sectional study. Swiss Med Wkly. 2014;(144):w13992. http://doi.org/10.4414/smw.2014.13992 
21. Szecsenyi J, Rosemann T, Joos S, Peters-Klimm F, Miksch A. German diabetes disease management programs are appropriate for restructuring care according to the chronic care model: an evaluation with the patient assessment of chronic illness care instrument. Diabetes Care, 2008;31(6):1150-4. http://doi.org/10.2337/dc07-2104

22. Spicer J, Budge C, Carryer J. Taking the PACIC back to basics: the structure of the Patient Assessment of Chronic Illness Care. J Eval Clin Pract. 2010;18:307-12. http://doi.org/10.1111/j.1365-2753.2010.01568.x

23. Rosemann T, Laux G, Droesemeyer S, Gensichen J, Szecsenyi J. Evaluation of a culturally adapted German version of the Patient Assessment of Chronic Illness Care (PACIC 5A) questionnaire in a sample of osteoarthritis patients. J Eval Clin Pract. 2007;13:806-13. http://doi.org/10.1111/j.1365-2753.2007.00786.x

24. Gugiu C, Coryn CL, Applegate B. Structure and measurement properties of the patient assessment of chronic illness care instrument. J Eval Clin Pract. 2010;14:509-16. http://doi.org/10.1111/j.1365-2753.2009.01151.x

25. Noel PH, Jones S, Parchman ML. Patient experience in an era of primary care transformation: revisiting the PACIC. Eur J Pers Cent Healthc. 2016;4:528-40.

26. Fan J, McCoy RG, Ziegenfuss JY, Smith SA, Borah BJ, Deming JR, et al. Evaluating the structure of the patient assessment of chronic illness care (PACIC) survey from the patient's perspective. Ann Behav Med. 2014;49:104-11. http://doi.org/10.1007/s12160014-9638-3

27. Taggart J, Chan B, Jayasinghe UW, Christl B, Proudfoot J, Crookes P, et al. Patients Assessment of Chronic Illness Care (PACIC) in two Australian studies: structure and utility. J Eval Clin Pract. 2011;17:215-21. http://doi.org/10.1111/j.1365-2753.2010.01423.X

28. Drewes HW, de Jong-van Til JT, Struijs JN, Baan CA, Tekle FB, Meijboom BR, et al. Measuring chronic care management experience of patients with diabetes: PACIC and PACIC+ validation. Int J Integr Care. 2012;12:e194. http://doi.org/10.5334/ijic.862

29. Aung E, Ostini R, Dower J, Donald M, Coll JR, Williams GM, et al. Patient assessment of chronic illness care (PACIC) in type 2 diabetes: a longitudinal study. Eval Health Prof. 2016;39:185-203. http://doi.org/10.1177/0163278714556674

30. Iglesias K, Burnand B, Peytremann-Bridevaux I. PACIC instrument: disentangling dimensions using published validation models. Int J Qual Health Care. 2014:26:250-6o. http://doi.org/10.1093/intqhc/mzu042

31. Cramm JM, Nieboer AP. Factorial validation of the Patient Assessment of Chronic Illness Care (PACIC) and PACIC short version (PACIC-S) among cardiovascular disease patients in the Netherlands. Health Qual Life Outcomes. 2012;10:104. http://doi. org/10.1186/1477-7525-10-104

32. Schwenke M, Welzel FD, Luck-Sikorski C, Pabst A, Kersting A, Blüher M, et al. Psychometric properties of the Patient Assessment of Chronic Illness Care measure (PACIC-5A) among patients with obesity. BMC Health Serv Res. 2019;19:61. http://doi. org/10.1186/s12913-019-3871-1

33. Gugiu PC, Coryn C, Clark R, Kuehn A. Development and evaluation of the short version of the Patient Assessment of Chronic Illness Care instrument. Chronic Illn. 2009;5:268-76. http://doi.org/10.1177/1742395309348072

34. Goetz K, Freund T, Gensichen J, Miksch A, Szecsenyi J, Steinhaeuser J. Adaptation and psychometric properties of the PACIC short form. Am J Manag Care. 2012;18: 55-60.

35. Alharbi N, ALsubki N, Alotabi M, Alotabi F, Alharbi N. Patient Assessment of Chronic Illness Care-Arabic (PACIC-Arabic) [Internet]. Adapted from the Patient Assessment of Chronic Illness Care (PACIC) @ 2004, The MacColl Center for Healthcare Innovation, Kaiser Permanente; 2018 (http://www.improvingchroniccare.org/index.php?p=Translations\&s=360, accessed 17 February 2019). 